\title{
RF-MEMS Switch Design and Analysis with Photon Crystal Structure
}

\author{
Mingxin Song and Rui Wu \\ Harbin University of Science and Technology \\ wuruiguaiguai19@163.com
}

\begin{abstract}
In this paper, a new structured switch based on photon crystal is designed, whose structure is notable in enhancing RF system performances. Experiment demonstrates that the new structure switch is of excellent transmission characteristics relative to average structures. In the end, the switch $S$ parameters' analysis and some design rules are given. When $T=50 \mu \mathrm{m}$, the inserting wave loss is reduced by 20\%, and the signal transmission efficency can be improved greatly.
\end{abstract}

Keywords: microelectromechanical device; transmission line measurements; switched systems

\section{Introduction}

With the development of communication technology, traditional switches cannot meet the increasing requirements, while RF-MEMS switches catch people's attention. RFMEMS switch has the advantages of low inserting loss, high isolation and so on, which fit for the future radio frequency system development. Due to the repeated movement of the switch, so the aging failure would be resulted at last. In this paper, we only focus on applications of point of transmission performance of the switch, such as the missile launching. About the aging failure is mentioned in some papers, such as the RF MEMS switch reliability and failure analysis written by Yongxian Guo in 2007. It will be notable to enhance the RF system performances and will be widely applied in outer space exploration and military defense. At present, its commercialization is hindered by the problem of high return wave loss and low signal transmission. Photon band gap structure is a hot research topic in micro-wave and millimeter-wave field in recent years. Photon band gap structure is also called photon crystal which is formed by a dielectric material distributed periodically with another dielectric material. This structure has a considerable frequency width by changing photon crystal periodicity [1]. In addition, photon crystal structure has low return wave loss and inserting wave loss. In this paper, we adopt onedimensional photon crystal structure for dielectric layer of RF-MEMS switch, and the performance and structure parameters are simulated and optimized. The photon crystal structure has important application value in micro wave circuit field [2]. Therefore, theoretical analysis and calculation of photon crystal structure is important to RF-MEMS switch.

\section{RF-MEMS switch principle}

\subsection{The Switch Working Principle}

The traditional RF-MEMS switch transmits signal by CPW (Coplanar Waveguide), the anchor support the movable metal plate which permits to have a space between metal plate and substrate [3]. Figure 1 is the vertical view of RF-MEMS swtich. And the switch cross section view is shown in Figure 2 and 3. The bias voltage is applied to the terminal 
of the metal plate in order to change the coupling capacitance between the metal plate and the substrate. Thus the signal transmission is controlled by the bias voltage. The magnitude of the bias voltage is determined by the space between metal plate and structural parameters.

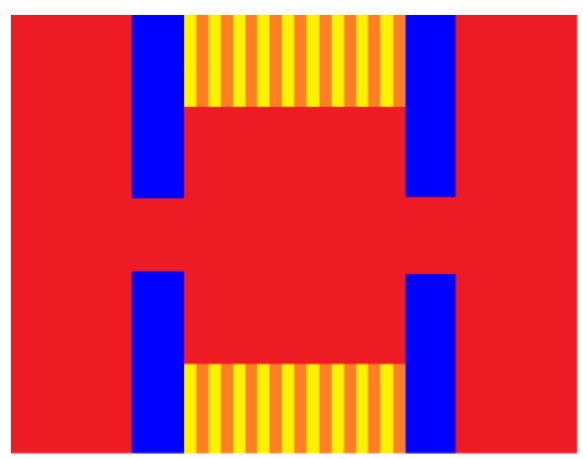

\section{Figure 1. The Vertical View of RF-MEMS Switch}

When the bias voltage is zero, the total capacitance is in minimum, and the signal can pass the CPW easily. The total capacitance of the switch is expressed as in Formula 1.

$$
\mathrm{C}_{\mathrm{Up}}=\frac{\varepsilon_{0} \mathrm{~A}}{\mathrm{~g}_{0}+\mathrm{t}_{\mathrm{d}} / \varepsilon_{\mathrm{r}}}
$$

In the Formula $1, A$ is the metal plate facing area, $\varepsilon_{0}$ is the air dielectric constant, $\mathrm{g}_{0}$ is the initial distance between movable plate and insulating dielectric layer, $t_{d}$ is the thickness of $\mathrm{Si}_{3} \mathrm{~N}_{4}$ layer, $\varepsilon_{\mathrm{r}}$ is the relative dielectric constant.

When bias voltage is applied to the movable plate, the metal plate moves down and the total capacitance increases accordingly. The capacitance radio of RF-MEMS switch in "on" and "off" state is as follows [4]:

$$
\frac{\mathrm{C}_{\text {Down }}}{\mathrm{C}_{\mathrm{Up}}}=\frac{\varepsilon_{\mathrm{r}} \mathrm{g}_{0}+\mathrm{t}_{\mathrm{d}}}{\mathrm{t}_{\mathrm{d}}}
$$

In general, the metal electrode movement is influenced by residual stress also, and residual stress is mainly affected by the deposition condition of the membrane on the top of sacrificial layer. Base on this consideration, the moveable metal membrane is made very thin usually.

The RF-MEMS switch based on photon crystal structure studied in this paper includes six components. They are $\mathrm{Si}$ substrate, $\mathrm{SiO}_{2}$ layer, transmission line, dielectric layer, fixed $\mathrm{Al}$ pad and movable metal electrode, as shown in Figure 2.

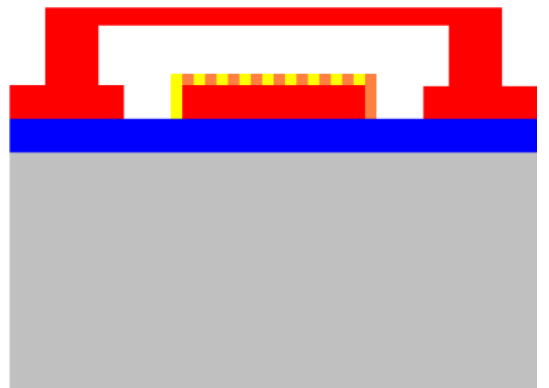

Figure 2. The Cross Section View of "on" State of RF-MEMS Switch

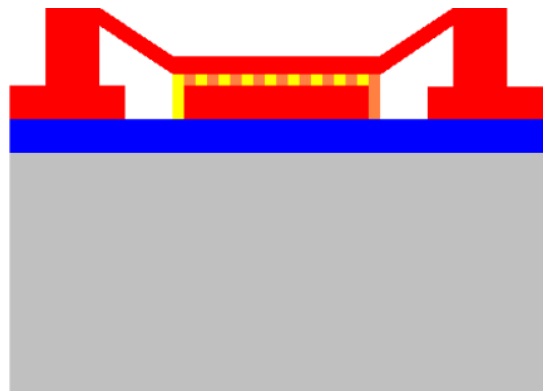

(1)

Figure 3. The Cross Section View of "off" State of RF-MEMS Switch 
When the driven voltage equals to 0 , the switch is on, RF signal passes through the transmission line. The signal has low return loss from one terminal to another terminal on the transmission line [5]. When driven voltage is higher than $10 \mathrm{~V}$, the upper movable plate moves down and contact to dielectric layer. The signal escapes to the metal plate. The switch cross section view is shown in figure 3. The key component of the switch-dielectric layer in this design uses photon crystal structure by distributing $\mathrm{SiO}_{2}$ in $\mathrm{Si}_{3} \mathrm{~N}_{4}$ periodically. Photon crystal is a man-made micro structure and is also called as photon bandgap material. It has approximately the same electron wave function with semiconductor lattice. Besides, it can modulate corresponding wavelength electromagnetic wave. When the electromagnetic wave transmits in photon bandgap material, it is modulated by Prague scattering, and then the energy band is formed. Some research proved that photon crystal micro strip line has low loss and high transmission efficiency [6].

\subsection{Switch Performance Parameters}

Inserting loss

In transmission system, load power is produced by inserting devices inside transmission system and the power loss caused by the inserting devices is defined as inserting loss. It refers to the receiving power ratio when inserting device into the transmission system. Ideally, the signal should have low inserting loss. However, in real cases, due to the influences of resistor and inductance, the transmission line produces inserting loss more or less which can lead to extra signal power decay

\section{Return loss}

Return loss is produced by impedance mismatch in transmission line. Usually mismatching occurs in the contact area. The return loss may result in instability of the transmission system and extra power consumption.

\section{Natural frequency}

When an object is in the state of free vibration, the displacement with time changes according to the sine law, the vibration amplitude and initial phase related to the initial conditions of the vibration. The cycle and the frequency do not have any relation with the initial condition but the nature character of the object itself. The natural frequency depends on the stiffness, mass and appearance of the object. When the object deformed, elastic makes it recovering to its initial shape. The high stiffness produces high natural frequency. The nature frequency of RF-MEMS depends on the structure and materials of the switch. For the sake of high reliability in high frequency conditions, the natural frequency characters should be taken into consideration. In general, the nature frequency of the switch should be more than $10^{4} \mathrm{~Hz}$ [7].

\section{Switch fabrication}

The Si micro mechanic processing technology is the foundation of MEMS device fabrication. If there is no corresponding Si processing way, MEMS devices cannot be accomplished. [8] So when design the MEMS devices, the fabricating process should be taken into consideration first. In 1980, K.E. Petersen concluded and divided them into three main ways which is called surface micro mechanic processing technology. 


\section{Experiment Simulation}

The switch inserting loss and return wave loss is simulated by utilizing the software CST with different dielectric layer thickness. The switch performances and characters are optimized using simulation result.

The simulation adopts the switch structure parameters, length $=1000 \mu \mathrm{m}$, width $=300$ $\mu \mathrm{m}, \quad \mathrm{Si}$ substrate thickness $=200 \mu \mathrm{m}$, signal line width $=100 \mu \mathrm{m}$, dielectric layer thickness $=1 \mu \mathrm{m}$, movable metal electrode $=100 \mu \mathrm{m}$, plates distance $=2 \mu \mathrm{m}$.

\subsection{Single Dielectric Micro-wave Parameters Simulation}

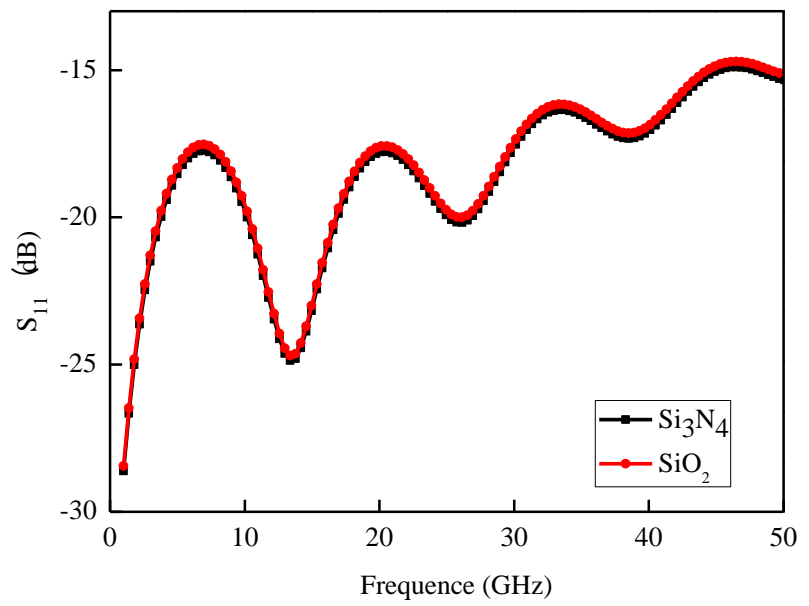

Figure 4. $S_{11}$ Parameter of a RF-MEMS Switch with a Single Dielectric Layer

Figure 4 shows the simulation result of the relationship between the return wave loss $\left(\mathrm{S}_{11}\right)$ and frequency for dielectric layers of $\mathrm{Si}_{3} \mathrm{~N}_{4}$ and $\mathrm{SiO}_{2}$. The two curves are quite similar. When frequency is $13.369 \mathrm{GHz}$, the switch return wave loss is $-24.86 \mathrm{~dB}$ when dielectric layer is $\mathrm{Si}_{3} \mathrm{~N}_{4}$ and $-24.69 \mathrm{~dB}$ when dielectric layer is $\mathrm{SiO}_{2}$. When second harmonic frequency is $26.137 \mathrm{GHz}$, the return wave loss is $-20.2 \mathrm{~dB}$ and the return wave loss is relative high at this time. Moreover, the difference between fundamental wave and second harmonic is small, which produces a little inhibition to harmonic. At this moment, the second harmonic frequency is the same with $\mathrm{Si}_{3} \mathrm{~N}_{4}$ layer, and return wave loss is $20 \mathrm{~dB}$. Due to the small inhibition action, $\mathrm{SiO}_{2}$ layer is not adopted.

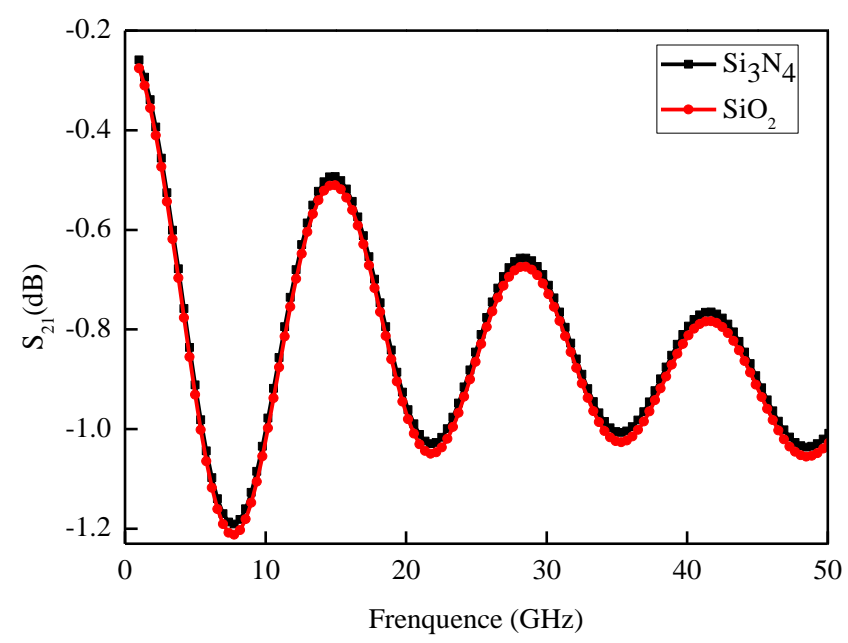

Figure 5. $\mathrm{S}_{21}$ Parameter of a RF-MEMS Switch with a Single Dielectric Layer 
Figure 5 shows the simulation result of the relationship between the switch inserting loss $\left(\mathrm{S}_{21}\right)$ and frequency for dielectric layers of $\mathrm{Si}_{3} \mathrm{~N}_{4}$ and $\mathrm{SiO}_{2}$. Again, the two curves are quite similar. When the return wave loss reaches the minimum value, i.e. $13.369 \mathrm{GHz}$, the inserting loss is $-0.683 \mathrm{~dB}$ when dielectric layer is $\mathrm{Si}_{3} \mathrm{~N}_{4}$ and the inserting loss is $-0.69 \mathrm{~dB}$ when dielectric layer is $\mathrm{SiO}_{2}$. But the big inserting loss can influence the quality of signal transmission and transmission efficiency; may result in degradation of switch performances.

From above analysis, we know that when dielectric layer is $\mathrm{Si}_{3} \mathrm{~N}_{4}$ or $\mathrm{SiO}_{2}$, the switch return wave loss and inserting loss can never reach an ideal value. So we adopt photon crystal structure as dielectric layer to increase the signal transmission efficiency.

\subsection{Photonic-crystal Micro-wave Parameters Simulation}

\section{1. $S_{11}$ parameter when photon crystal dielectric material in different period}

Figure 6 shows the simulation result of relationship between the return wave loss and frequency for $1 \mathrm{D}$ photon crystal structure of $\mathrm{Si}_{3} \mathrm{~N}_{4}$ and $\mathrm{SiO}_{2}$ with various periods for $\mathrm{T}$ equals to $100 \mu \mathrm{m}, 66.7 \mu \mathrm{m}, 50 \mu \mathrm{m}, 40 \mu \mathrm{m}, 33.3 \mu \mathrm{m}, 25 \mu \mathrm{m}$ and $20 \mu \mathrm{m}$, respectively. The width of $\mathrm{Si}_{3} \mathrm{~N}_{4}$ is equals to the width of $\mathrm{SiO}_{2}$ and equals half the period $\mathrm{T}$. It can be seen from Figure 6 that when micro-wave frequency equals to $13.369 \mathrm{GHz}$, the return wave loss is at its minimum as $-24.9 \mathrm{~dB}$ when dielectric material distribution period is $100 \mu \mathrm{m}$. And the second harmonic return wave loss is $-20.1 \mathrm{~dB}$, the difference between fundamental wave and second harmonic $S_{11}$ parameter is $4.8 \mathrm{~dB}$, which is bigger than single dielectric layer and benefit to signal transmission. While dielectric material distribution period is $66.7 \mu \mathrm{m}$, the return wave loss is at its minimum as $-27.65 \mathrm{~dB}$ when the frequency is $13.369 \mathrm{GHz}$. The return wave loss difference between fundamental wave and second harmonic is $5.89 \mathrm{~dB}$. Due to the relative low return wave loss and an appropriate difference, the crystal structure is a good choice for RF-MEMS dielectric material.

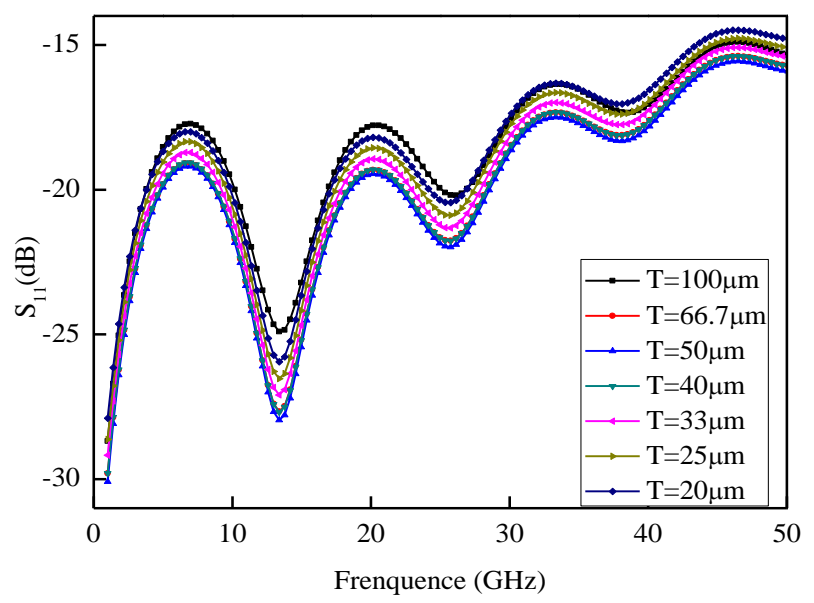

\section{Figure 6. $S_{11}$ Parameter of a RF-MEMS Switch with 1D Photon Crystal with Different Periods}

For $\mathrm{T}=50 \mu \mathrm{m}$, the photon crystal is fairly uniform distributed, $\mathrm{S}$ parameter reach optimal state. And the return wave loss is $-27.76 \mathrm{~dB}$ when frequency is $13.369 \mathrm{GHz}$, the return wave loss is $-21.77 \mathrm{~dB}$ when the second harmonic frequency is $25.738 \mathrm{GHz}$. The return wave loss is low and beneficial to signal transmission, at either the fundamental frequency or at second harmonic frequency. Moreover, the return wave loss difference between fundamental wave and second harmonic is large enough to restrain disturbance. 
Thus, $\mathrm{T}=50 \mu \mathrm{m}$ of the photon crystal structure is a good choice for RF-MEMS switch dielectric layer.

When the period equals to $40 \mu \mathrm{m}, 33.3 \mu \mathrm{m}, 25 \mu \mathrm{m}$ and $20 \mu \mathrm{m}$, on the other hand, The minimum return wave loss at $13.369 \mathrm{GHz}$, and the return wave loss difference between fundamental wave and second harmonic are larger than that of $\mathrm{T}=50 \mu \mathrm{m}$.

2. $S_{21}$ parameter when photon crystal dielectric material in different period

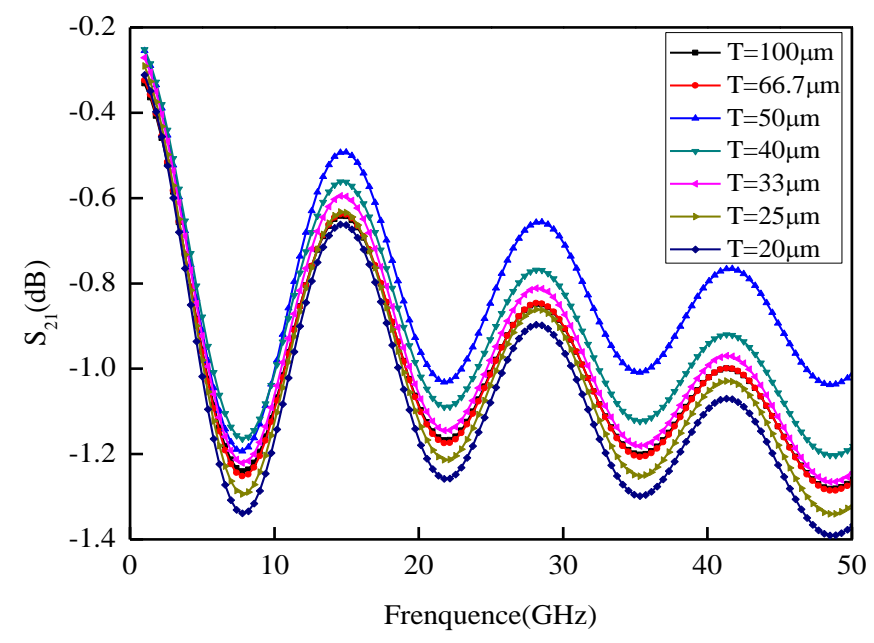

\section{Figure 7. $S_{21}$ Parameter in a RF-MEMS Switch with 1D Photon Crystal Different Periods}

Figure 7 shows the relationship of inserting loss and frequency in 1D photon crystal structure with $\mathrm{T}=100 \mu \mathrm{m}, \mathrm{T}=66.7 \mu \mathrm{m}, \mathrm{T}=50 \mu \mathrm{m}, \mathrm{T}=40 \mu \mathrm{m}, \mathrm{T}=33 \mu \mathrm{m}, \mathrm{T}=25 \mu \mathrm{m}, \mathrm{T}=20 \mu \mathrm{m}$. At $13.369 \mathrm{GHz}$, the inserting loss is $-0.67 \mathrm{~dB}$ for $\mathrm{T}=100 \mu \mathrm{m}$ and inserting loss is $-0.6 \mathrm{~dB}$ for $\mathrm{T}=66.7 \mu \mathrm{m}$, which are bigger compared to that of single dielectric layer; and are beneficial for signal transmission. For $\mathrm{T}=50 \mu \mathrm{m}$, the inserting loss is $-0.55 \mathrm{~dB}$ at $13.369 \mathrm{GHz}$, which has little effect on signal transmission. When $\mathrm{T}$ is smaller than $50 \mu \mathrm{m}$, inserting loss is lower, which can lead to a low transmission efficiency.

3. Return loss in different period

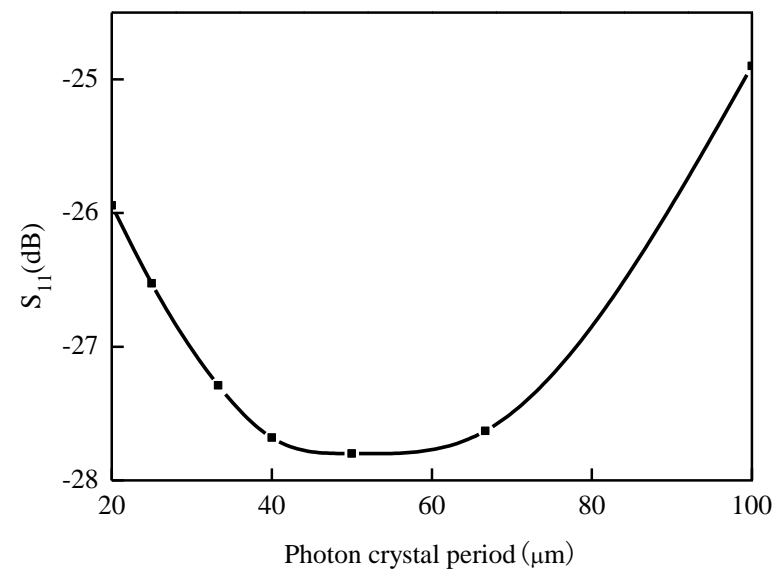

Figure 8. $S_{11}$ Parameter vs. Photon Crystal Period

Figure 8 summarizes the $S_{11}$ parameters as a function of 1D photon crystal periods ranging from $20 \mu \mathrm{m}$ to $100 \mu \mathrm{m}$. It can be seen in Figure 14 that when the period increases, 
the return wave loss decreases and then increases. The curve in Figure 14 resembles a parabola with a minimum near $\mathrm{T}=50 \mu \mathrm{m}$. The return wave loss is in minimum of $-27.76 \mathrm{~dB}$ at $\mathrm{T}=50 \mu \mathrm{m}$. When the period is less than $50 \mu \mathrm{m}$, the return loss decreases quickly. When the period is bigger than $50 \mu \mathrm{m}$, the return loss also increases quickly.

4. Inserting loss in different period

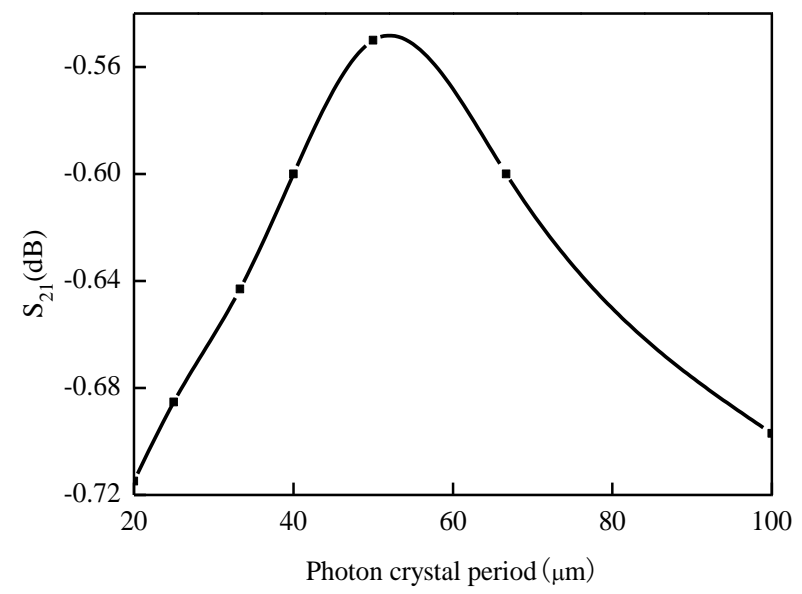

Figure 9. $S_{21}$ Parameter vs. Photon Crystal Period

Figure 9 shows the relationship of $S_{21}$ parameter as a function of 1D photon crystal periods. The inserting loss increase first, as the period increases and reaches a peak at $\mathrm{T}=50 \mu \mathrm{m}$; as the period increases further, the inserting loss decreases. At $\mathrm{T}=50 \mu \mathrm{m}$, the quality of signal transmission in the RF-MEMS switch is in the highest.

\section{Conclusion}

The signal transmission performances of RF-MEMS switch with 1D photon crystal structures is studied using CST technique and $\mathrm{S}$ parameters simulation results are obtained. The simulation results show that the RF-MEMS switch with 1D photon crystal structure has better performance for signal transmission compared to that with single dielectric layer. In addition, the RF-MEMS switch performance as a function of 1D photon crystal periods is investigated and the return wave loss and inserting loss were simulated for different periods ranging from $20 \mu \mathrm{m}$ to $100 \mu \mathrm{m}$. The simulation analysis result indicates that when $\mathrm{T}=50 \mu \mathrm{m}$, the RF-MEMS switch has the best signal transmission compared to others. RF-MEMS switches with 2D and even 3D photon crystal structures will be investigated in the future.

\section{Acknowledgements}

This work is supported by Science and Technology Research Project of Education Department of Heilongjiang Province (Grant No. 12511076).

\section{References}

[1] M. Yang and C. L. Da, "Capacitive RF switches manufactured by the CMOS-MEMS technique", Microelectronic Engineering, vol. 88, no. 8, (2001) August, pp. 2242-2246.

[2] J M. Kim, C G. Cheon and Y W. Kwon, "A hybrid RF MEMS probe array system with a SP3T RF MEMS silicon switch for permittivity measurement", Journal of Micromechanics and Microengineering, vol. 18, no. 8, (2008), August, pp. 1-6.

[3] Z. Zhang, X. Liao and H. Lei, "A coupling RF MEMS power sensor based on GaAs MMIC technology", Sensors and Actuators, vol. 160, no. 1-2, (2010) May, pp. 42-47. 
[4] I. D. Wolf, W. M. Van and S. P. Gen, "Techniques to study the reliability of metal RF MEMS capacitive switches", Microelectronics Reliability, vol. 42, no. 9-11, September-November (2002) pp. 1789-1794.

[5] C. L. Goldsmith, A. Malczeweki and Z. J. Yao, "RF MEMS Variable Capacitors for Tunable Filters", International Journal of RF and Microwave Computer-Aided Engineering, vol. 9, no. 4, (1999), pp. 362374.

[6] C. Goldsmith, N. Randall, S. Esbelman, T H. Lin and D. Denniston, "Characteristics of micro machined switch at microwave frequencies", Microwave Symposium Digest, vol. 2, (1996) June, pp. 1141-1144. Available: http://ieeexplore.ieee.org/xpls/abs_all.jsp?arnumber=511231

[7] V. Bezooijen and A. De Jongh, "A GSM/EDGE/WCDMA adaptive series-LC matchig network using RF-MEMS switches", IEEE Journal of Solid-State Circuits, vol. 43, no. 10, (2008) October, pp. 22592268. Available: http://ieeexplore.ieee.org/xpls/abs_all.jsp?arnumber=4639526

[8] C L. Chang and P Z. Chang, "Innovative micro machined microwave switch with very low insertion loss". Sensors and Actuators, vol. 79, no. 1, (2000) January, pp. 71-75. 